\title{
THE ACTION OF GLYCEROL ON MICROCOCCI FROM
} EPIDEMIC POLIOMYELITIS

\author{
George Mathers and George H. Weaver \\ From the Memorial Institute for Infectious Diseases, Chicago
}

During the past year certain micrococci have been demonstrated in the tissues of the central nervous system of persons dead with epidemic poliomyelitis, and there is some evidence at hand indicating that these organisms bear some relation to the disease. Since the causative agent of poliomyelitis has been found to be highly resistant to the action of glycerol it seemed important to determine whether these micrococci possessed the same resisting power for this mild bactericide. The purpose of this brief communication is to present the results of a few experiments bearing on this problem.

In this work cultures of poliomyelitic cocci were compared with different strains of streptococci and pneumococci with reference to their power to resist the bactericidal action of glycerol. The organisms used included 2 strains of micrococci isolated from the spinal cord of poliomyelitis cases, 2 strains of hemolytic streptococci from scarlet fever, 2 strains of Streptococcus viridans from the throats of measles patients, and 1 strain of pneumococcus. Three experiments were made.

In the first experiment the different micro-organisms were grown on blood-agar slants for 24 hours, and the growth of each culture suspended in sterile $50 \%$ glycerol. These suspensions were kept at a temperature of 3-5 C., and cultures made at regular intervals. In Exper. 2 the different micro-organisms were grown on blood-agar slants for 24 hours and the surfaces of the slants were then covered with sterile $50 \%$ glycerol. These cultures were kept in the refrigerator at a temperature of 3-5 C. and cultures made from them at regular intervals. The results of Expers. 1 and 2 are shown in Table 1.

When the bacteria were grown for 24 hours on blood-agar slants and suspended in sterile $50 \%$ or full strength glycerol, they refused to grow after about 3 weeks. The pneumococcus was less resistant than the others, dying in about 2 weeks. One strain of the poliomyelitic coccus remained alive for 30 days. From the blood agar slant 
cultures of these organisms which were covered with $50 \%$ glycerol positive cultures were obtained after 3 months from all the tubes.

In Exper. 3 the brains and spinal cord of each of two cases of poliomyelitis were placed in 50\% glycerol on Sept. 5, and Sept. 9, 1916, respectively. These tissues have been kept in the refrigerator and cultures have been made at monthly intervals since that time. After 15 months both strains of poliomyelitic cocci were alive and easily obtainable by culture from the glycerolated tissues. The organisms obtained in these cultures were similar in morphology and cultural characters to those of the primary cultures. Rabbits injected intravenously with large doses of these cultures were not affected. The primary cultures of both strains obtained at necropsy in the same dosage, however, produced death of rabbits with changes suggestive of those of poliomyelitis.

TABLE 1

The Action of Glycerol on Cultures of Poliomyelitic Cocci and Other Organisms

\begin{tabular}{|c|c|c|}
\hline Organism & $\begin{array}{c}\text { Period of Viabilty } \\
\text { When Suspended in } \\
50 \% \text { Glycerol }\end{array}$ & $\begin{array}{l}\text { Period of Viability on } \\
\text { Blood-Agar Slant Cov } \\
\text { ered with } 50 \% \text { Glycerol }\end{array}$ \\
\hline $\begin{array}{l}\text { Poliom yelitic coccus No. } 1 \\
\text { Poliomyelitic coccus No. } 7 \\
\text { Streptococcus scarlet fever No. } 1 \\
\text { Streptococcus scarlet fever No. } 2 \\
\text { Streptococcus viridans No. } 1 \\
\text { Streptococeus viridans No. } 2 \\
\text { Pneumococeus }\end{array}$ & $\begin{array}{l}30 \text { days } \\
21 \text { days } \\
21 \text { days } \\
21 \text { days } \\
21 \text { days } \\
21 \text { days } \\
14 \text { days }\end{array}$ & $\begin{array}{l}90 \text { days } \\
90 \text { days } \\
90 \text { days } \\
90 \text { days } \\
90 \text { days } \\
90 \text { days } \\
90 \text { days }\end{array}$ \\
\hline
\end{tabular}

CONCLUSIONS

Poliomyelitic cocci as well as pneumococci, hemolytic streptococci and Streptococcus viridans when suspended in 50\% glycerol remain viable for 15-30 days. In the presence of a suitable culture medium such as blood agar, however, cultures of these organisms may remain alive for 90 days.

In two instances poliomyelitic cocci were obtained in culture from the glycerolated nervous system of cases of poliomyelitis after a period of 15 months.

It seems probable then that the micrococci associated with poliomyelitis similar to the virus of the disease, are highly resistant to the bactericidal action of glycerol in 50\% solution.

It is interesting to note that ordinary streptococci and pneumococci are also markedly resistant to this germicide. 